\title{
A Study on Team-based Learning Based on Wechat Public Platform: The Case of Design and Implementation of Mass Media Management Course
}

\author{
Jian $\mathrm{Ma}^{{ }^{*}}{ }^{*}$ Zhenyu $\mathrm{Wu}^{2}$ \\ ${ }^{1}$ School of History, Culture\& Tourism, Southwest Minzu University, Chengdu, 610041, Sichuan, P. R. CHINA \\ ${ }^{2}$ School of law, University of Monpellier, Montpellier, FRANCE
}

Received 12 June 2017 • Revised 20 August 2017 • Accepted 20 September 2017

\begin{abstract}
Team-based learning encouraging team cooperation, characterized by active participation, focusing on open discussion is an important teaching method to stimulate students' initiative, enthusiasm and creativity, and to cultivate teamwork spirit, problem solving ability and language skills. The design and implementation of the course need to focus on decentralization, rules, mechanism and communication.
\end{abstract}

Keywords: Wechat public platform, team-based learning, talent training, teaching reform

\section{INTRODUCTION}

Since Tencent's launch of free instant messaging application-Wechat in January 2011, the app's popularity and influence have been increasing. According to the Research Report on Chinese Social Media User Behavior 2015 released by China Internet Network Information Center (2016), the proportion of respondents who use Wechat is $69.1 \%$ in all types of mobile instant messaging tools, second only to the proportion of QQ users (close to 75.8\%). According to a random survey of 2,500 college students in 208 colleges and universities in 28 provinces (autonomous regions and municipalities) by Zheng (2014), the proportion of students using Wechat was $84.7 \%$. This means that Wechat enjoys a high awareness and utilization rate among the college students. In order to make students better understand and master new media content production and operations, in the course of Mass Media Management for majors of Management of Cultural Industries in Southwest Minzu University, we tried to adopt a team-based learning, and achieved preferable effects.

\section{LITERATURES REVIEWING}

Since Senge (1990) proposed the concept of team-based learning earlier in The Fifth Discipline, research on teambased learning has been widely distributed in psychology, pedagogy, organizational behavior, human ergonomics and other disciplines. Senge (1990) pointed out that team-based learning is not only one of the most important forms of organizational learning, but also the ability to develop group members to cooperate and improve the goal completion ability. As the basis for organizational learning, team learning has played a very active role in enhancing organizational learning ability (Edmondson, 2002), improving organizational effectiveness (Wilson, Goodman, \& Cronin, 2007) and coping with environmental changes (Rose, 2011).

With the deepening of research, research on team-based learning has been broadened in three directions. First, learning information processing emphasizes that team-based learning is the process in which team members reprocess and recycle the information. For instance, Offenbeek (2001) deemed team-based learning as a cyclic process consisting of information access, information distribution, information processing, information dissemination and information storage. Wilson et al (2007) argued that team-based learning behavior mainly includes information storage, information sharing and information acquisition. Second, learning behavior deems team-based learning as some kind of interactive behavior among team members. For instance, Edmondson (1999) argued that team-based learning is the process in which team members jointly identify problems, analyze problems, and ultimately give problem solutions. Andres et al (2010) defined team-based learning as a series of activities 


\section{Contribution of this paper to the literature}

- Decentralization allows students to freely form study groups (operation team), and freely choose the theme and content with the "greatest common divisor", so that "interest" naturally becomes the teacher of team-based learning group.

- In order to prevent the free rider problem, it is necessary to urge each student to contribute their talents and sweat to study groups through institutional design. Since there is only one quota for each grade, students can only improve their grades by raising the coefficient and improving the total score, and actively participating in classroom discussions.

- Benign competition mechanism is an important method to stimulate students' enthusiasm for learning. In view of the inter-team and intra-team competition, the process of team-based learning is not only a process of barely dealing with operations, but also a process for better performance.

- Because the whole class is engaged in the same content of learning and practice, there is a lot "common language" among "peer" students, which avoids the sense of alienation from unfamiliar business scenarios in the traditional case discussion.

including information exchange, formation of programs, comparison of programs, selection of programs and consensus. Third, learning results emphasize that team-based learning is the result of knowledge transfer between team members. For instance, Ellis et al (2003) argued that team learning is the sharing of knowledge and experience among team members and is a process of raising the overall level of knowledge based on team level. Edmondson et al (2007) emphasized the results of team-based information processing and learning improvements that teambased learning includes. Lin (2016) developed a model for an effective combination of online peer assessment and videos via Facebook groups, and found that the combination of online peer assessment and micro-teaching videos likely enables pre-service teachers to significantly increase their perceived learning about teaching competency over time. But his study relied on self-reported survey data, could not use multiple data sources or triangulation to strengthen the conclusions, what significantly affected the credibility of this study.

As a very common instant messaging service app in China, Wechat research in classroom education is mainly conducted in China. Meng and Chen (2014) discussed the feasibility of applying Wechat public platform to mobile teaching in colleges and universities, and put forward the relevant functional design scheme and key technical route. The study of Shan, Tan and Xue (2015) found that, on the one hand, the Wechat public platform helped to attract students' attention, promote personalized learning and real-time assessment of learning outcomes; on the other hand, there are problems such as poor communication between students, low learning resource conversion rate, and weak controllability of learning behavior. Wu \& Ding (2017) discussed the advantages of WeChat software which is applied to college English mobile learning, and the construction of College English mobile learning platform based on the WeChat model. In general, research on the application of Wechat public platform in teambased learning is still rare.

\section{RESEARCH DESIGN}

The traditional teaching of Mass Media Management is more about the operation of newspapers, magazines, radio and television. However, with the rise of new media, the world media pattern has undergone a subversive change, the importance of new media is growing. In addition, the traditional Mass Media Management teaching process of partial theory teaching and partial traditional media has become increasingly outdated. To this end, we have drastically reformed the teaching of Mass Media Management course (see Table 1).

Table 1. Basic ideas for teaching reform of Mass Media Management

\begin{tabular}{ll}
\hline Frame & Content \\
\hline Origin & Practice hands-on ability by operating the Wechat public account. \\
\hline Request & Topics and contents are not limited, better related with college students. \\
\hline System & Group (team) cooperation system under leadership. \\
\hline \multirow{2}{*}{ Feedback } & $\begin{array}{l}\text { Week teaching and biweekly discussion. The class explores various problems encountered in the operation of the } \\
\text { Wechat platform. }\end{array}$ \\
\hline $\begin{array}{l}\text { Group report, site login and PPT presentation. Group rankings and ratings based on subscriptions and maximum } \\
\text { single-article click reading volume of Wechat public account. The results of the team members are assessed by } \\
\text { the team leader based on their contribution. Specifically divided into four grades (coefficients): excellent (1.0), } \\
\text { good (0.8), medium (0.6), poor (0.5). Personal score is obtained through multiplying individual coefficient by team } \\
\text { results. Each level has a quota of } 1 \text { person, the group leader's coefficient is 1.0. }\end{array}$ \\
\hline
\end{tabular}




\section{Taking Students as the Team Cooperation Subject}

In the process of team-based learning, students are the subject of team-based learning and the discoverer and constructor of knowledge. Teachers are the designers, teaching organizers and guides of team-based learning plan. Students choose the theme and content of the Wechat public platform that they are interested in, and freely set up a study groups (operation teams). Through course learning, classroom discussion and after-school practice, we explore the full range of knowledge from content to management in the operation process of Wechat public platform, so as to fundamentally change the traditional one-way teaching mode where teachers are the knowledge communicators and students are passive receivers.

\section{Characterized by Team-Based Learning}

In the teaching organization of team-based learning, the class is divided into 5-student study groups (operation teams), each group has a team leader, responsible for the operation and management of the team and given scores. Group ratings are assessed by the team leader based on their contribution. Specifically divided into four grades (coefficients): excellent (1.0), good (0.8), medium (0.6), poor (0.5). Each level has a quota of 1 person. Personal score is obtained through multiplying individual coefficient by team results, the group leader's coefficient is 1.0. As a result, there is a cooperative and competitive relationship between the various groups of the same class and between the members of the same group.

\section{Centered by Participatory Research}

In the traditional teaching process of management courses, case teaching method is the main way for students to actively integrate into classroom discussion. However, this method is more suitable for students with relevant work experience. In fact, at the beginning of the teaching reform, we have also adopted case teaching method, but the effect was not ideal. Many students simply could not understand the business context and dilemma described in the case material, let alone to put forward solutions in the absence of social or work experience. After the indepth communication between teachers and students, study groups (operation teams) were set up, taking Wechat public platform as a "quasi-venture project", gaining a comprehensive and systematic learning of mass media management related knowledge through deep study of the development, growth and maturity process of new media (Wechat public account).

\section{Focused on Open Discussion}

In the classroom teaching of team-based learning, the organization of exciting and efficient open discussion is the driving force of stimulating students' enthusiasm. First, the whole class is the actual participant of the study groups (operation teams), no one is an outsider, and secondly, the groups will carry out an open report of the operations every two weeks while ensuring that everyone has the opportunity to speak. After reporting on recent developments and difficulties, all students are encouraged to submit their comments and suggestions based on their own experiences and experiences (plus points). Finally, the teacher made comments and summaries based on the report and open discussion of study groups, and put forward recommendations and expectations for the next one or two weeks.

\section{DISCUSSION}

According to Mass Media Management course design, team-based learning process not only includes classroom learning, but also covers extracurricular practice. In the case of the Wechat public account "I am a girl" operation by team 5, class 1301 of Management of Cultural Industries in Southwest Minzu University in the second discussion, the team's reporter reported the following questions:

First, the Wechat public account encountered difficulties in its application for approval. In response to this question, we continued to re-upload the documents for review, and developed a plan to reapply a new public account in case the first account failed to pass. Second, difficulties in pre-promotion and public attention. Subscribers are mainly friends of the group members, and friends helped to recommend to their friends. Therefore, we need to actively looking for new subscription groups while maintaining the existing subscribers. Third, the article click rate is not high. The number of subscribers was 208 two weeks after the Wechat public account "I am a girl" was opened, but the article click rate was far from the total number. In response to this question, we prepared to share the article link to Wechat moments, QQ space and Weibo, so as to get more readers and followers. However, they do not intend to send the "contact card" through mass texting, in order to prevent reducing the popularity of the account. Forth, the unfollowing phenomenon. Four people have unfollowed two weeks after "I 
Table 2. Summary of the operation team of Wechat public account "School Sis Punster"

\begin{tabular}{|c|c|}
\hline Presenter & Speech content \\
\hline Li & $\begin{array}{l}\text { My biggest gain is that I gradually cultivated my sense of humor...In fact, my dream is to be an amateur actor, } \\
\text { through this platform, I can get closer to it, and my ultimate goal is match with Marilyn Monroe! }\end{array}$ \\
\hline Guo & $\begin{array}{l}\text { I hope to get on a higher level through this platform, and to make a living by "School Sis Punster", wish it can sell a } \\
\text { good price. }\end{array}$ \\
\hline Wang & $\begin{array}{l}\text { I can always burst into laughing while looking for funny videos, as long as it can make everyone happy. In the } \\
\text { beginning, me and mate Adai thought we can get on a higher level, though now it seems not like what we thought, } \\
\text { we still hope to bring you joy. }\end{array}$ \\
\hline Kang & $\begin{array}{l}\text { We can't realize our dreams off life, because the dreams of life. Taking part in the team, I try to work with others, } \\
\text { and release myself. In the past, I couldn't image I can play such a crazy character, just with friends I can do like this. } \\
\text { We are not black swans, nor do we want to be them, we just walk with them shoulder to shoulder. }\end{array}$ \\
\hline Qiu & $\begin{array}{l}\text { Remember how rash we were to publicize on our social platform even before the first article was notified, tried all } \\
\text { means we could. Later, our teacher enlightened us by saying that "content is the core element of development", to } \\
\text { create contents that truly attract the public is the key to determine the healthy development of a Wechat public } \\
\text { platform or a cultural enterprise! There is disagreement, but more joy, because we all have a heart to make this } \\
\text { "child" thrive. We tried to overcome the difficulties through timely adjustment. This is a long-term homework, and } \\
\text { the first time for me! We certainly will enter the burnout period to the end, but how to mobilize the enthusiasm of } \\
\text { each partner is a question worth pondering. Fortunately, school students are loyal fans of the Cultural Industries } \\
\text { with entertainment spirit, and they can find new inspirations in each video shooting! Maybe at first we were just } \\
\text { trying to get a good final grade, but in the end, "School Sis Punster" was no longer an assignment for us. We made } \\
\text { up the titles through brainstorming, and shot surprisingly funny videos to amuse our subscribers. Perhaps the idea } \\
\text { was not so novel, the text appeared stiff, but "School Sis Punster" came today after bit by bit effort! People around } \\
\text { us said we truly pulled it together, but we also learned too much in the process. Whether from the basic knowledge } \\
\text { of the Wechat platform and the use of software, or how to communicate with the users and partners, more } \\
\text { importantly, we harvested the priceless joy and friendship! }\end{array}$ \\
\hline Team & $\begin{array}{l}\text { We would like to thank the } 273 \text { users that followed us, and we should not let them down in the future! The users } \\
\text { are everything, Wechat Thinking said: the mission of Wechat is to connect everything. Wechat platform connects } \\
\text { the users of "School Sis Punster" and us. We would also like to pay special tribute to the students from class } 1301 \text { of } \\
\text { Management of Cultural Industries who have continued to encourage us and make constructive suggestions. } \\
\text { Because of you, we made progress step by step in the exploration! Thank our six relatives and friends, who took the } \\
\text { trouble to endure our publicity and forward, although you may not be interested, you still showed great patience } \\
\text { and gave us ideas! Finally, thank you teacher Ma Jian! Thank you for giving us such a remarkable homework, they } \\
\text { say you were so ruthless at the beginning, but we want to say, thank you for your "ruthlessness"! There is a saying } \\
\text { that: how we look at the world decides what we see the world. Teacher, thank you for letting us see a pretty } \\
\text { different world! }\end{array}$ \\
\hline
\end{tabular}

am a girl" was opened, in response to this question, we prepared to continually improve the content, making it more detailed and more attractive, while stabilizing existing subscribers and attracting more subscribers.

In the specific mode of operation, we took a division of labor responsibility system under the leadership of one person (team leader), make regular content notifying three times a week (Monday, Wednesday, Friday) and timely contact with customers to understand their needs. When a problem is encountered, team members discuss and find a workable solution and make timely adjustments. Experience shows that students not only learned knowledge, but also experience in the process of team-based learning (see Table 2).

\section{CONCLUSION AND RECOMMENDATION}

Team-based learning is an important teaching way to stimulate students' initiative, enthusiasm and creativity, and to develop teamwork spirit, hands-on ability and language skills. Our practice of teaching reform by means of Wechat public platform shows that it cannot only allow students to learn professional knowledge through researchstyle learning, enables students to cultivate hands-on ability by facing problems solving them, and develop students' written and verbal skills through Wechat content creation and open discussion in the classroom. The success of team-based learning largely depends on the overall design and implementation of course. Our study found that in the course of the design and implementation process, four aspects need to be paid particular attention:

Firstly, decentralization, which allows students to freely form a study group (operation team), and freely choose the theme and content with the "greatest common divisor", so that "interest" naturally becomes the teacher of team-based learning group. At the same time, the free team forming also makes it easier for team members to live in harmony and cooperation.

Secondly, rules. In order to prevent the occurrence of the free-rider problem, it is necessary to urge each student to contribute their talents and sweat to study groups through institutional design. Since there is only one quota for 
each grade, students can only improve their grades ( $30 \%$ of the total term-end score) by raising the coefficient (the team leader score) and improving the total score (group score), and actively participating in classroom discussions (with extra points).

Thirdly, mechanism. Benign competition mechanism is an important means to stimulate students' enthusiasm for learning. In view of the inter-team and intra-team competition, the process of team-based learning is not only a process of barely dealing with operations, but also a process for better performance. The student's return is not only reflected in the grades, but also in the sense of accomplishment and satisfaction brought by the successful operation of Wechat public account.

Forth, communication. Because the whole class is engaged in the same content of learning and practice, the process of learning is also very similar. Therefore, there is a lot of "common language" among "peer" students, so as to avoid the sense of alienation from unfamiliar business scenarios in the traditional case discussion. Thanks to the bonus points of speaking and opportunities for equal discussion, students are also happy to share their experiences and thoughts.

Concern and attention to these four aspects will greatly enhance the effect and effectiveness of team-based learning based on Wechat public platform.

\section{ACKNOWLEDGEMENTS}

This work was supported by the Soft Science Foundation of Chengdu municipal Bureau of science and technology (Grant No. 2015-RK00-00007-ZF), Project of Key Research Institute of Philosophy and Social Science in Sichuan-Modern Design and Culture Research Center (Grant No. MD15Z003), Project of Teaching Research and Reform in Southwest Minzu University(Grant No.2014YB25), the Fundamental Research Funds for the Central Universities, and the Research Funds of Southwest Minzu University (Grant 2017SZYQN22).

\section{REFERENCES}

Andres, H. P., \& Shipps, B. P. (2010). Team learning in technology-mediated distributed teams. Journal of Information Systems Education, 21(2), 213-221.

Celic, I., Yurt E., \& Sahin, I. (2015), A Model for Understanding Educational Facebook Use, Eurasia Journal of Mathematics, Science \& Technology Education, 11(4), 899-901. doi:10.12973/eurasia.2015.1447a

China Internet Network Information Center (2016). The report on user behavior of social application in China (2015). Beijing: China Internet Network Information Center, 13.

Edmondson, A. C. (1999). Psychological safety and learning behavior in work teams. Administrative Science Quarterly, 44(2), 350-383. doi:10.2307/2666999

Edmondson, A. C. (2002). The local and variegated nature of learning in organizations: A group level perspective. Organization Science, 13(2), 128-146. doi:10.1287/orsc.13.2.128.530

Edmondson, A. C., Dillon, J. R., \& Roloff, K. S. (2007). Three perspectives on team learning. The Academy of Management Annals, 1(1), 269-314. doi:10.1080/078559811

Ellis, A. P. J., Hollenbeck, J. R., Ilgen, D. R., Porter, C. O. L. H., West, B. J., \& Moon, H.(2003). Team learning: Collectively connecting the dots. Journal of Applied Psychology, 88(5), 821-835. doi: 10.1037/0021-9010.88.5.821

Lin, G. Y. (2016), Effects that Facebook-based Online Peer Assessment with Micro-teaching Videos Can Have on Attitudes toward Peer Assessment and Perceived Learning from Peer Assessment, Eurasia Journal of Mathematics, Science \& Technology Education, 12(9), 2295-2307. doi: 10.12973/eurasia.2016.1280a

Meng, F. 1., \& Chen, L. (2014). Research on the Construction of Mobile Learning Space Based on We Chat Public Platform. Modern Educational Technology, 24(10), 19-25. doi: 10.3969/j.issn.1009-8097.2014.10.003

Offenbeek, M, V. (2001). Processes and outcomes of team learning. European Journal of Work and Organizational Psychology, 10(3), 303-317. doi:10.1080/13594320143000690

Rose, K. H. (2011). Learning for success: How team learning behaviors can help project teams to increase the performance of their projects. Project Management Journal, 42(2), 96-96. doi:10.1002/pmj.20236

Senge, P. M. (1990). The fifth discipline: The art and practice of the learning organization. New York: Doubleday Current.

Shan, F., Tan, x. h., \& Xue, K. (2015). Mobile Micro-learning Research Based on the We Chat Public Plat form. Open Education Research, 21(1), 97-104.

Wilson, J. M., Goodman, P. S., \& Cronin, M. A. (2007). Group learning. Academy of Management Reviews, 32(4), 10411059. doi:10.5465/AMR.2007.26585724 
Wu, J., \& Ding, Z. R. (2017), Research on Mobile Learning Model of College English Based on WeChat Platform, Eurasia Journal of Mathematics, Science \& Technology Education, 13(8), 5847-5853. doi:10.12973/eurasia.2017.01034a

Zheng, X. N. (2014). An investigation and analysis on the current situation of WeChat using by college students, Ideological \& Theoretical Education, (2), 83-86.

\begin{abstract}
APPENDIX
The Mass Media Management is an applied course with equal emphasis on theory and practice. In the course of one teaching semester, a teaching mode that theory teaching every single week and problems discussing every fortnight is gradually formed, which combine organically with theory instruction in classroom, Classroom discussion and WeChat running after school.

Through the way of students forming a study group (operation team) and operating Wechat Public Platform, they deeply understand the theory of mass media management in practice, thereby that can stay indoors but learn more about the details of the operation and management of new media, and the students' learning interest and practical ability are well cultivated.

This course has also become a popular subject. The student evaluation scores of the course are 4.990, 4.975 and 4.998, ranking first, third and first in the whole school respectively, in the second semester of 2014-15 academic year, the first semester of 2015-16 academic year and the second semester of 2015-16 academic year.
\end{abstract}

\title{
http://www.ejmste.com
}

